\title{
Family visits to libraries and bookshops: observations and implications for digital libraries
}

\author{
Nicholas Vanderschantz, Claire Timpany, Annika Hinze, Sally Jo Cunningham \\ Dept. of Computer Science, University of Waikato, \\ Private Bag 3105, Hamilton New Zealand \\ \{vtwoz, ctimapny, hinze, sallyjo\}@waikato.ac.nz
}

\begin{abstract}
This paper explores how families select books for leisure reading. We recruited 17 families (adults and children) for this study, and spent time with each in both bookshops and public libraries. Our research aims to add to understanding of how families interact with books and bookshelves in these places, and how digital libraries might best support the shared needs of these inter-generational users. Much of our understanding of how an eBook should look and feel comes from generalizations about books and assumptions about the needs of those individuals who read them. We explore how children and adults search and browse for books together, with specific focus on the type of information seeking tasks that families undertake and on the families' shared search and browsing strategies. We further explore the implications of this study for the development of digital libraries for children and families.
\end{abstract}

Keywords: participant observation, social space, collaborative information behaviour, families.

\section{Introduction}

We report here on an observational study exploring how family groups interacted with books in both library and bookshop environments. We aim for an added understanding of families' book selection strategies in these places, to provide insight into how digital libraries could be designed to support the collaborative family behaviour observed in physical environments.

We conducted interviews and observations with 17 family groups who each visitied both a public library and a bookshop. Previous investigations of children's information behaviour have rarely focussed on recreational reading and family groups. Similarly, most digital libraries for children focus on supporting the needs of an individual child searching for a book on their own. We see in this present study and in an earlier study [1] that for children, the practice of searching for a book is often far more social than individual. The process of search, interaction and decision making is often completed in collaboration with, or, alongside a parent or sibling.

The remainder of the paper is structured as follows: Section 2 discusses related work on children and book/ebook selection in physical and digital libraries. Section 3

adfa, p. 1, 2011.

(C) Springer-Verlag Berlin Heidelberg 2011 
describes our study methodology and Section 4 presents the results of our study. We analyse our findings in Section 5, and discuss implications for DL in Section 6.

\section{$2 \quad$ Related Work}

Large et al. [2] observe that the childhood years have a strong impact on both the reading levels of children and their ability to navigate a library. As children mature they form strategies for selecting books collaboratively and individually. Family information needs can broadly be divided into two categories: education books and leisure books $[2,3]$. Search for and selection of education books is usually initiated by a third party such as a teacher wanting students to respond to an assignment [4]. Leisure books are typically self-selected by the child or family and selection is motivated by personal interests. Reading books not directly associated with homework has been found to encourage families to enjoy reading and to read more for both pleasure and learning [5].

\subsection{Book search and selection strategies}

Cunningham [1] found that younger children clearly selected books on the basis of serendipitous encounters that match a preference, rather than actively employing a strategy to search for books of a particular genre, theme, author, or other characteristic. Similarly, Raqi and Zainab [6] observe that the strategy most frequently employed by children was browsing the (physical) library shelves. Books of interest are then usually identified based on the cover, genre, author, series, print size, number of pictures and pages, and colourful cover illustrations. Information seeking in printed resources typically follows the two stages of selecting an appropriate source and finding the information within it [2]. Children were observed to follow two methods to evaluate a non-fiction book: the 'sequential access' of flipping through the pages to find information and 'selective access' using the content page or the index [7]. Sequential access was used when the book was short, the child was interested in the entire book or even when a younger child was seeking particular information. Selective access was used for thicker books, or to find particular items of information.

\subsection{Social aspects of book finding}

Another strategy used by children is to request assistance to locate desired book topics, authors and series [6]. This was observed especially in children who are still developing their reading skills. Fogget [8] noted that children would request help from friends, family or librarians once they had exhausted their own information resource of browsing the shelves. In an anonymous observation study Hinze et al. [9] noted that many family visitors to a public library seemed to be "spending time". In 24 of the 56 family groups observed by Hinze et al., children were observed playing, sometimes with items from the library (including pillows, a rocking horse, puzzles, 
books, and paper and scissors), or with items they brought along (such as mobile phones and iPads). Hinze et al. also described the library as seemingly providing a place for parents to meet with other adults in an environment that offered distraction or entertainment for their children. Cunningham [1] observed that for children finding a book is very rarely a solitary activity; instead, they visit bookshops and libraries with parents, siblings, and friends. She noticed how young children bring books back to adults for reading and approval; friends and siblings give advice to each other (both encouragement and warnings); and parents offer recommendations and guidance. Retrospective studies often comment on the strong influence of recommendations by others, but largely do not capture the rich behaviour, as observed by Cunningham. Our study aims to add to the insights gained from her observational study.

\subsection{Digital Libraries for children}

The work on the International Children's DL (ICDL) focusses on providing interfaces for searching and browsing the Digital Library in a manner appropriate for children. Reuter and Druin [10] found that children were able to navigate hierarchies in browsing, but that visual Boolean search, which had been developed to avoid the need for correctly-spelled keywords, remained generally underused. Visual/graphical DL interfaces have also been successfully employed for an Indian village DL aimed at user groups with low textual literacy [11]. The social aspect of book finding has begun to be explored for inter-generational co-design in digital libraries [12], though the collaborative aspects are still ill-supported in existing DL.

\section{Method}

We invited 17 families to visit both a library and a bookshop, to observe how they interacted with the physical space, bookshelves and books. The focus for this study was on the book selection process of the family group.

We interviewed families pre- and post- observation, and members of the family groups at times interacted directly with the researcher in an informal talk-aloud style. The pre-interview involved meeting with the parent and child/ren at their home or at a location chosen by the family. The aim of the first meeting was twofold: researchers would be involved in the whole process of planning the visit and the visit itself, and the child/ren could build confidence and familiarity with the researcher and therefore would be more likely to have natural interactions during the observations. This meeting also gave the opportunity for the researcher to conduct an interview with the parent covering basic demographic information as well as the types of books they have in their home and the reading behaviours of the family.

The observations occurred at both libraries and bookshops located in Hamilton and Tauranga, New Zealand. Each family chose the bookshop and library that they would visit during the study. The researcher encouraged each familiy to choose a bookshop and library to visit based on familiarity of the envirionments to the family. Three different libraries were visited, two in Hamilton (Garden Place Library - F1 \& F3, 
and Chartwell Library - F2) and one library in Tauranga (Tauranga City Library - F4 - F17). All families chose to visit the children's sections of the library except for group F4 with an 11 year old boy who chose to visit the Teen Section of the Tauranga City Library. Five different book shops were chosen by the families, Whitcoulls, Center Place Hamilton (F1), Books for Kids, Hamilton (F2, F3), Books a Plenty, Tauranga (F4, F5, F12), Whitcoulls, Davenport Rd, Tauranga (F6, F7, F10, F11, F13, F14, F17), and Paper Plus, Grey St, Tauranga (F8, F9, F15, F16). Whitcoulls and Paper Plus are both nationwide chain book stores in New Zealand, while Books a Plenty is a Tauranga based independent book seller and Books for Kids is Hamilton based independent bookshop speacialising in books for children. All book shops were single-storey buildings; the chain stores were considerably bigger than the independent bookshops.

The observations involved the researcher following the family group during the process of selecting books and noting the interactions that occur in the book selection process. It was explained to participants that they were in no way obliged to purchase or loan a book at any stage. The researcher followed the parent and child/ren for the complete duration of their visit to the library or bookshop. Our researcher noted how the participants moved around the physical space, which shelves they looked at, what features of the books they used to help them with selecting, and their interactions with each other.

The researcher was a silent participant during the visits, unless directly engaged by a family member. Sometimes the children interacted with the researcher, usually in a 'stream-of-consciousness' type of explanation of their activities, about their selection decisions and book preferences. One child in group F13 read the blurb of a book to the researcher and the child in F2 asked the researcher to read him a book he had selected.

Finally, a short semi-structured interview followed the observation to gain further understanding of the interactions that had been observed.

\subsection{Participant Sample}

Seventeen family groups participated in the study, each of which completed an observational session in a public library and a bookshop. Participant families were recruited through personal invitation, via word of mouth and through a general participant call. No selection criteria was applied to the participant families that responded to the recruitment invitations. It is likely that only active readers agreed or self selected to participate in the study. Discussion of the reading habits of the participants is outlined in Section 4.1 of our paper.

In the 17 family groups there were a total of 35 children; 22 male and 13 female. Six of the children were alone with the parent, seven were in pairs and 4 were in groups of 3 or 4 children (see Table 1). The children's ages ranged from 2 years to 11 years, with most children between 5 and 11 years. All accompanying adults except two were mothers (F1 was a female Au Pair and F12 was the father in this family). The observations were scheduled at the convenience of the families who volanteered to participate without remuneration. For this reason, the families nominated the 
parent(s) or guardian(s) who would participate in the study with their children. While we did not sitpulate when observations should be conducted, all families chose to participate in the observations before $5 \mathrm{pm}$ on a week day and this may be indicative of the choice of which guardian or parent participated.

Table 1. Overview of all participant groups

\begin{tabular}{|c|c|c|c|c|c|c|c|c|c|c|c|c|c|c|c|c|c|}
\hline Family & F1 & F2 & F3 & F4 & F5 & F6 & F7 & F8 & F9 & F10 & F11 & F12 & F13 & F14 & F15 & F16 & F17 \\
\hline Parent & $P(F)$ & $P(F)$ & $P(F)$ & $P(F)$ & $P(F)$ & $P(F)$ & $P(F)$ & $P(F)$ & $P(F)$ & $P(F)$ & $P(F)$ & $\mathrm{P}(\mathrm{M})$ & $\mathrm{P}(\mathrm{F})$ & $P(F)$ & $P(F)$ & $P(F)$ & $P(F)$ \\
\hline Children & $\begin{array}{l}A(M, 2) \\
B(M, 5)\end{array}$ & $A(M, 3)$ & $A(M, 4)$ & $A(M, 11)$ & $\begin{array}{l}A(F, 5) \\
B(F, 9)\end{array}$ & $\mid \begin{array}{c}\mathrm{A}(\mathrm{F}, \mathrm{7}) \\
\mathrm{B}(\mathrm{M}, \mathrm{9}) \\
\mathrm{C}(\mathrm{M}, 11)\end{array}$ & $\begin{array}{l}A(M, 5) \\
B(F, 9) \\
C(F, 11)\end{array}$ & $A(M, 9)$ & $\begin{array}{l}A(M, 6) \\
B(M, 9)\end{array}$ & $\begin{array}{l}A(M, 2) \\
B(F, 9)\end{array}$ & $\begin{array}{l}A(F, 5) \\
B(M, 9)\end{array}$ & $\begin{array}{c}A(M, 5) \\
B(F, 7) \\
C(M, 10 a) \\
D(M, 10 b)\end{array}$ & $\begin{array}{l}A(F, 9) \\
B(F, 11)\end{array}$ & $\begin{array}{l}\mathrm{A}(\mathrm{M}, 6) \\
\mathrm{B}(\mathrm{M}, 7) \\
\mathrm{C}(\mathrm{M}, 8) \\
\mathrm{D}(\mathrm{F}, 9)\end{array}$ & $A(M 10)$ & $\begin{array}{l}A(M, 7) \\
B(F, 8)\end{array}$ & $A(M, 9)$ \\
\hline
\end{tabular}

\section{Results}

Here we present the results of our interviews and observations.

\subsection{Interviews}

In the initial interview, families with children of up to nine years old reported to read with their child either daily or every second day. Most of the 10 and 11 year olds still read frequently, but independently of their parents. Nine families read with at least one of the children daily, one family twice a week, five families 3 or 4 times a week and 2 families had children who were now independent readers only. Five of the 15 families who read with their youngest children also described their older children as independent readers who did not participate in the shared reading with the parents. 11 parents stated they personally read daily, four parents stated they read two to three times a week, one parent stated twice a week and one parent stated they read once a week.

The frequency of visits to the library varied greatly across the 17 families (see Fig. 1). Over half of the families would visit the library once or more during a month. Some commented that while as a family they may only visit once a month, or less frequently throughout the year, over school holidays they would visit every week as part of a school holiday programme. Three of the families responded that they would visit the mobile library as a family once a fortnight, but their child would visit the school library with their class every week. Overall, participants reported on visiting a bookshop less frequently than a library. One participant described that the family would visit a bookshop together only when they had a voucher (no frequency was given). One mother said she would only visit a bookshop without her children. 


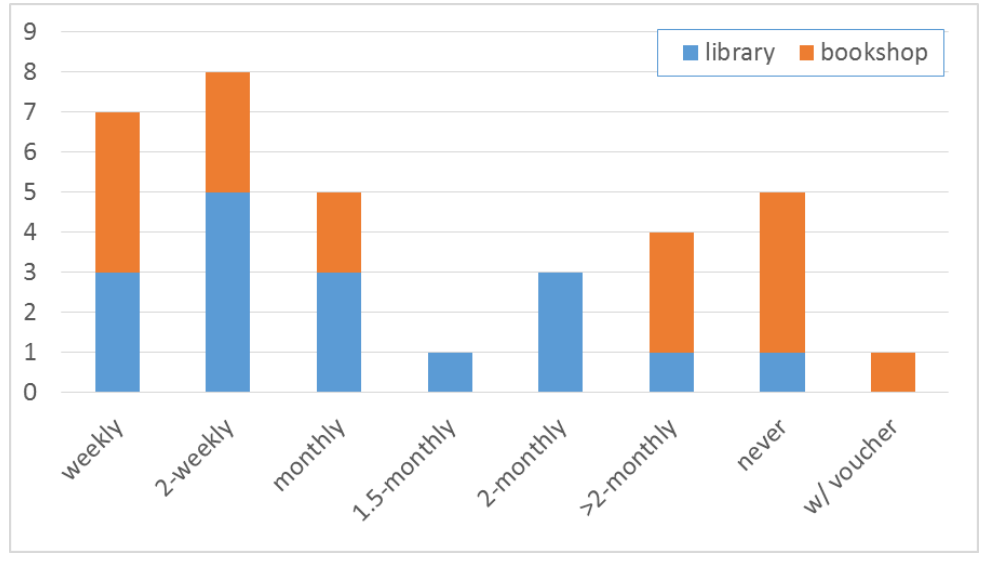

Fig. 1. Frequency of family visits to library and bookshops

\subsection{Observations}

The researcher went together with the families to the bookshops and libraries. From the pre-observation interviews we learned that only two families (F2 \& F4) indicated that they were not looking for anything in particular this day, either in the library or the bookshop, and just wanted to browse. Nine families (F1, F5, F6, F7, F8, F12, F13, F16) had a particular series in mind to look for. Six families were interested in books by a specific author (F9, F10, F12, F13, F14, F17). Eight families were intending to look for books on a particular subject (F3, F6, F7, F10, F11, F12, F15, F17), and only 2 had a specific title in mind that they wanted to search for (F8 \& F14).

The length of time for the observations in a library ranged from 15 to 60 minutes with a mean length of 40.8 minutes. Most observations lasted approximately 45 minutes. The length of time for the observations in a bookshop ranged from 10 to 45 minutes with a mean length of 18.8 minutes. Most observations lasted approximately 15 minutes.

There was no correlation between age of children and the length of time they spent in the bookshop or library. F1 with a 2 and a 5 year old spent 45 minutes in the library, while F2 with a 2 year old spent only 20 minutes. Neither did the number of children determine the length of the stay, nor their habit of regularly visiting the library (F3 went every week and F4 went never though both groups stayed for 45 minutes in the library).

Collaborative vs individual search. The observed searching for, interacting with, and decision about books were considered to be collaborative if the child/ren interacted with the parent or asked the librarian or bookshop person for assistance. We analysed the predominant interaction pattern of each family group for bookshop and library, resulting in the overview shown in Table 2. 61 of 102 possible interaction types were collaborative or used a mixture of collaborative and individual searching, interacting or decision making. 
Table 2. Individual (I, blue) vs collaborative (C, orange) interaction patterns (* indicates mix)

\begin{tabular}{|c|c|c|c|c|c|c|c|c|c|c|c|c|c|c|c|c|c|c|}
\hline & Family & $F 1$ & $F_{2}$ & F3 & F4 & F5 & F6 & F7 & F8 & F9 & F10 & F11 & F12 & F13 & F14 & F15 & F16 & F17 \\
\hline \multirow[t]{2}{*}{ Search } & Library & $\mathrm{c}$ & 1 & c & 1 & 1 & 1 & 1 & $\mathrm{c}$ & 1 & c & 1 & c & c & 1 & $\mathrm{c}$ & 1 & $\mathrm{c}$ \\
\hline & Bookshop & c & c & 1 & 1 & 1 & c & c & 1 & c & $\mathrm{c}$ & 1 & c & 1 & 1 & c & 1 & c \\
\hline \multirow[t]{2}{*}{ Interaction } & Library & c & c & c & c & c & 1 & 1 & * & 1 & 1 & 1 & 1 & 1 & $\mathrm{c}$ & c & 1 & c \\
\hline & Bookshop & c & c & c & 1 & * & 1 & c & 1 & c & $\mathrm{c}$ & c & $\mathrm{c}$ & * & c & 1 & 1 & 1 \\
\hline \multirow[t]{2}{*}{ Decisions } & Library & c & c & c & 1 & * & 1 & c & * & c & 1 & 1 & c & * & 1 & 1 & 1 & c \\
\hline & Bookshop & c & c & c & 1 & * & * & ${ }^{*}$ & c & * & * & * & $\mathrm{c}$ & * & * & 1 & * & c \\
\hline
\end{tabular}

When we consider the reading ability of young children, it is perhaps unsurprising that for the children who were 5 years and younger, collaborative search was the prominent method of identifying books. In our study 9 of the children were 5 years old or younger. Therefore when we re-contextualize Table 2 we see in Table 3 that while collaborative decision making decreases substantially in both bookshops and libraries, collaborative search in the library is still common for families who do not include children 5 years old or younger.

Table 3. Individual (I, blue) vs collaborative (C, orange) interaction patterns (* indicates mix) broken down by family groups with younger members

\begin{tabular}{|c|c|c|c|c|c|c|c|c|c|c|c|c|c|c|c|c|c|c|}
\hline & & \multicolumn{10}{|c|}{ Families with 5 year olds and younger } & \multicolumn{7}{|c|}{ Families all members 5 years old+ } \\
\hline & Family & F1 & F2 & F3 & F5 & F7 & F9 & F10 & F11 & F12 & F14 & F4 & F6 & F8 & F13 & F15 & F16 & F17 \\
\hline \multirow[t]{2}{*}{ Search } & Library & c & 1 & c & 1 & 1 & 1 & c & 1 & c & 1 & 1 & 1 & c & c & c & 1 & c \\
\hline & Bookshop & c & c & 1 & 1 & c & c & c & 1 & c & 1 & 1 & c & 1 & 1 & c & 1 & c \\
\hline \multirow[t]{2}{*}{ Interaction } & Library & c & c & c & c & 1 & 1 & 1 & 1 & I & c & c & 1 & * & 1 & c & 1 & c \\
\hline & Bookshop & c & c & c & * & c & C & $\mathrm{c}$ & c & c & c & 1 & 1 & 1 & * & 1 & 1 & 1 \\
\hline \multirow[t]{2}{*}{ Decisions } & Library & c & c & c & * & c & c & 1 & 1 & c & 1 & 1 & 1 & * & * & 1 & 1 & c \\
\hline & Bookshop & c & c & c & * & * & * & * & * & c & * & 1 & * & c & * & 1 & * & c \\
\hline
\end{tabular}

Observed Behaviour Patterns. The level of involvement of parents with the children in both the library and bookshop visits varied greatly. At younger ages parents were generally highly involved with the child's book search, and also spent time to read with them or discuss the content of books (e.g., F1, F2, F4). Above a certain age the parental involvement went one of two ways: parents were either still highly involved, or left their children to be largely independent while they conducted their own search in the library or bookshop, or relaxed on a couch. Several parents (5 of 17) assisted their children in the library with their search for books by teaching them or introducing them to a library facility or book features that they had not previously used. Two of the parents (F13 and F15) showed their children of $9 \& 11$ years and 10 years, respectively, how to use the Dewey decimal system to help them find nonfiction books in a particular subject area they were interested. Another adult (F1) showed a 5 year old how to use the catalogue to find books in a series by a particular author, and helped him write down the reference and find to books on the shelf. One 
parent (F10) showed her children, 7 and 9 years, where the "Recent Returns" shelf was and suggested that this was a way to find books that were popular. A fifth parent explained to a 6 and 7 year old that reading the blurb on the back of a book can help with trying to decide if the book will be of interest (F14). Perhaps an effect of the self selection of the participants in our study, many of the parents appeared to be confident library users who supported their children in searching and showed knowledge in library and bookshop layout and use.

Overall, a wider range of actions were conducted in libraries (see Fig. 2) and many more reading-related activities were likely to occur in a library. The library is also used as a place to read books. Both more reading-related activities and more play was happening in the bookshops.

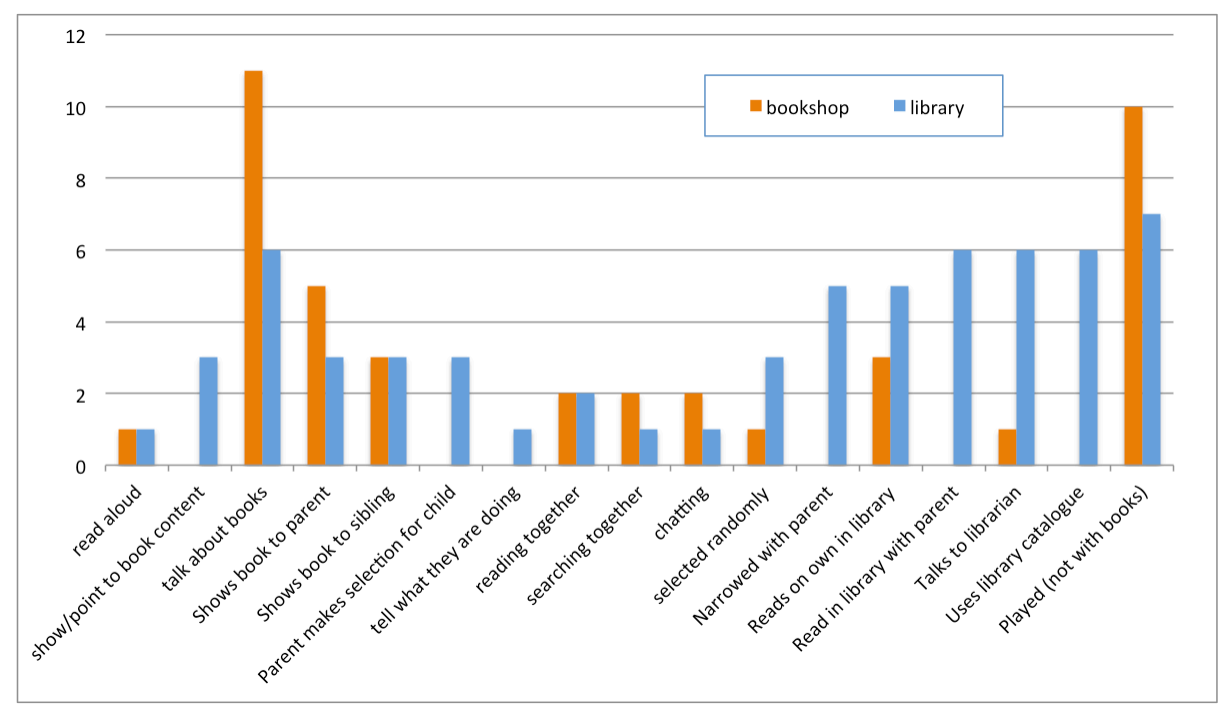

Fig. 2. Actions of children

Book Sampling Behaviour. The observed book sampling behaviours (in both libraries and bookshops) did not seem to be age specific. The main exception was the reading of the back cover (13 instances), which was mostly done by older children (aged 8-11 years). The youngest children in the study who were observed reading a book's back cover were 6 and 7 years old. They had just learned about it from their mother (F14) who encouraged them to read the blurb on the back of the book. The front cover was used by children across all ages (34 instances), with many children using the cover not just for initially deciding to look at the book (and taking the book off the shelf), but also as the sole means for assessing the content of the book. The mother of a 5 year girl stated that "[the girl] usually picks books with "girly covers" like animals or babies" (F11). The back cover was also used (13 instances) and use of the spine ( 6 instances) during book sampling. We also noted page-by-page flipping (16 instances), full book page flipping ( 7 instances) and use of the title or author (13 
instances) during decision making by children. Illustrations found within the book were also observed to be used as a regular feature (12 instances) to help children determine if they would like to read a book. Comments made by the two children who noted the number of pages in a book ( 2 instances) seemed to indicate that it was a way for them to assess how appropriate that book would be for their reading level or age. All of these sampling behaviours were conducted by the children, at times independently, or encouraged by the parent or older children in the group and at times as a method for sharing a decision or seeking guidance.

\section{Discussion}

We analysed the observation and interview data to determine how participants looked for books, how they interacted with books, how they made decisions, and how they interacted with each other. Here we briefly summarise our findings and compare them with results from related studies. We further explore how these insights might influence the way we design digital libraries.

We observed that families spent a much longer time in libraries than in the bookshop; this difference could be attributed to the fact that the space was more conducive to taking time with exploring and making choices, and that the children could select to take home a much larger number of books from the library than the bookshop. In the library our observations lasted two to three times longer than in the bookshop. This use of the library further supports the premise of third spaces in digital libraries discussed by Cunningham et al. [13].

\subsection{Searching and browsing}

Children in our study often looked for books that they recognised as being a part of a series written by an author the children were familiar with. This observation further supports the research previously conducted by Raqi and Zainab [6]. Children often commented that they had not read a series, but had heard friends talking about a series being good. Recognition of a book being part of a series was largely based on cover images or spine. Older children also knew that more information about a series could be available inside a book, where they looked for a list of other books in the series. Younger children also seemed to be drawn to books that were a part of a series, these books were commonly associated with a character with which they were familiar.

Collaborative search for books involved a parent and child walking along the shelves together, or two siblings looking for books in the same series, or an older sibling helping a younger sibling to find the book they want, or a parent showing a child/ren how to look for books in the library in a certain way. For most of the observed family groups, the search process appeared generally more collaborative in libraries than in bookshops. Our study provides here additional data, and confirms the findings from Cunningham [1].

Different from Raqi and Zainab [6] we also observed group members that were asking for help in using a library catalogue or a book feature. Only a very small 
number of children used the catalogue search in the library (6 groups) or asked for assistance from a staff member to search for books (6 in the library and 1 in the bookshop), preferring to browse the shelves to find what they are looking for. The child in family group F7 illustrated this behaviour when searching the shelves for a specific author without success and stated, "It will turn up". This preference for browsing and trust in visual serendipity may indicate that either children or parents find the catalogue keyword search (as also typically used in digital libraries) not to be an effective tool. Equally, it might mean that they had never tried or are unaware of the catalogue search. While we did not probe the reasons for this lack of catalogue use or interaction with staff, investigation into this will be of further interest to researchers in developing solutions for digital libraries.

\subsection{Interactions with books}

Front covers, back covers and illustrations were all book features used by participants when interacting with the books and deciding which books they were interested in issuing or purchasing. Large et al. [2] suggested that in a family situation either the 'sequential access' of flipping through the pages to find information or the 'selective access' of using the content or the index of a book to look for information are most commonly used to determine if a book will be good to read. In our observations both of these methods were used, however, 'sequential access' was predominant. Only one participant used a table of contents and none were observed to use an index. The most common type of 'selective access' was used by the older children in our study who were looking at the list of books in a series, printed at either the front or back of the book. Many children also read books aloud, or asked their parents to read to them. This was not necessarily for decision making, but rather a form of book consumption.

\subsection{Decision making}

The age of the child seemed be the biggest factor when making decisions about which books to select. Age was used as an indicator of 'appropriateness'. For older children the decision making process was generally done individually, whereas for younger children this was more often done in collaboration with a parent. Children seemed very aware of which age section they should be looking in. Some of the younger children did look at chapter books and picture books but only the older children (1011 years) went to the teenage section, others walked past it straight to the non-fiction books. Cunningham [1] observed visual cues in libraries and bookshops to indicate the age for which the books are suitable. We similarly observed that libraries and shops conveyed a geography that related to age and classification groupings.

\subsection{Social interactions}

In the library the majority of interactions revolved around selecting books or sitting down to read a chosen book. In the bookshops, many interactions revolved around either sharing funny parts of a book or reading a passage out loud. It also seemed that 
families were more likely to share a snippet from a book if they were not going to leave the library or store with the book. Some families stayed in the bookshop or library to read together: four families read in the library, and only one family read in the bookshop. The family reading in the bookshop did so in an area that provided beanbags for customers. Typical of New Zealand libraries, spaces for casual reading were supplied in all libraries that the families visited. Seating is not often found in New Zealand bookshops and this was also the case in those visited by families in our study, only one of the bookshops had a seating area for casual reading. For seven family groups, the behaviour patterns observed seemed to vary between the library and the bookshop, such as family group F10 who went from partaking in collaborative search, individual interaction and individual decisions in the library to being in the bookshop where they were searching individually, interacting collaboratively and then making individual decisions.

\subsection{Limitations \& further work}

The nature of the participant recruitment may be a factor influencing the type of participants that formed the sample of this study. It was likely that families who were active readers, and inevitably active users of libraries and bookshops would opt to participate in such a study. This may have resulted in a narrow view of shared use of these spaces. Arguably, however, these regular users of physical libraries and bookshops may also be, or become, the regular users of DL's in the future because of their typical reading practices.

The single visit to each environment with each family may also have given only a small sample of how a family typically uses these spaces. The impact of being observed may too have influenced interactions. A longitudinal study with a smaller sample of families is warranted in the extension of this work.

Our study focused on family wide interactions and does not follow individual members of the group. How individuals, specifically individual children, use these spaces would be of interest and benefit to the development of Digital Libraries. Equally, our recruitment did not attempt to ensure a spread of male and female guardians. Future studies may benefit from analysis of how, or if, different use of these spaces by different role models exists. Indeed, also of interest is if different role models interact with the children in these spaces differently.

It has been suggested by a reviewer of this paper that future work in this area may include interviewing librarians and bookshop personnel as experts to gain insight into our findings. We see this as sound advice and agree that such a comparison of experts' observations to our own will garner further implications for the development of future systems. We expect that there is also a need to further probe families about the use of digital or expert knowledge that is available in these environments and when and why these systems or experts are or are not used. 


\section{Conclusions: Implications for Digital Libraries}

This paper reports on a study in which we explored how 17 families select books for leisure reading in both bookshops and public libraries. Currently, much of our understanding of how an eBook should look and feel comes from generalizations about books and assumptions about the needs of those individuals who read them. Our paper explored how children and adults search and browse for books together.

We now analyse the implications of our observations on the design of eBooks and Digital Libraries. Our interviews revealed the need for inter-generational reading environments for children up to the age of 10 , who still read daily with their parents. We found that 10 and 11 year olds still read frequently, but more independently of their parents and may not need regular inter-generational support in a DL. This was also supported by our observations which showed that these young children were supported by their parents in their searches, while the older children were either supported or allowed to independently search. When a child conducted independent searches, adults often conducted their own searches, thus suggesting the need to facilitate parents' use of the DL even as the child becomes an independent searcher.

1. Strong visual references. The lack of catalogue search and the predominance of visual browsing as well as decision making based on cover images and illustrations, suggest that a digital library that caters for families needs to have very strong visual references to support decision making by young and old family members. We agree with the suggestion by Large et al. [2] that searches in digital libraries for children should not rely on linguistic methods but rather use visual indicators such as cover images. We would suggest designers of digital libraries for inter-generational use to go further and include other visual cues. These additional visual cues may include example illustrations and indication of the number of illustrations contained in a book and the size of a book, all of which might help families generate conversation around book content. Colour seems to have been understood by several children as an indicator for interesting books, and a digital library could support browsing based on colour.

2. Clear geography. Children seem to take their cues about the appropriateness or suitability of books not just from cover images and illustrations (addressed in 1 . above), but also from the spatial layout of the physical library. A digital library similarly might incorporate spatial areas for different ages, and sections for nonfiction and fiction books that are clearly visually marked. Similarly areas of related topics might be indicated visually. The ability to present information in a number of ways in a digital environment allows for overlapping geographies that serve the needs of family members of different age groups. Cunningham [1] previously noted that these spatial or geographical areas need to be consistent to support recognition.

3. Physicality of eBooks. Children in our study noted the length of books by either checking the number of pages or by estimating their length from the thickness of the spine. This is common in studies of both children and adults. A digital library needs to have a clear visual encoding of the length of a book to serve family members in making selection decisions. 
4. Series and recurring characters. Children were very keen on identifying books in a series. In a digital library, these connections between books should be identifiable and be visually clear. Because authors of books for children and youth often write for a number of age and interest levels, the ability to identify other books by an author, within a series or with a relationship to a family members interests would likely also serve other family members. Again, groups of books with similar bibliographic metadata should be presented spatially close.

5. Social interaction and recommendations. Many children selected books based on recommendations from friends, teachers or parents. In a DL, this would require some means of awareness of other people so that one could have information about books others read, or feedback on known or similar books. These might be restricted to a selected group such as family or school class, or open, similar to social, or commercial systems. Other social interaction observed in both library and bookshops were children exploring individually and returning to parents to show their finds or to receive help with selecting. Supporting these actions in a digital library means going beyond the concept of a child as the isolated user. The digital equivalent might not be restricted to synchronous interactions, so that, for example, grandparents could participate with their grandchildren in selecting books when not physically co-located.

6. Reading together. A number of family groups were observed reading together in the library or bookshops. Shared reading of interactive books enhance the ability for adults and children to engage in meaningful shared reading experiences that draw on both physical and intellectual enhancements in the stories to encourage discussion about the story and illustrations and the asking of questions [14]. Reading out loud or shared reading could be easily supported and would be of interest to small children who cannot read themselves. The support for the social interaction of being read to by a parent is harder to incorporate. Being able to record readings for a child might open new opportunities for relatives who live far away. As an extension of (5.) above, synchronous but remote interaction in which a child selects a book and a, say, grandparent may record a reading or that book, may open up new opportunities for social interaction involving books.

We suggest here design extensions to digital libraries that go beyond designing for children only, but rather embrace the concept of a library as a third place for shared family use. We noted previously that bookshops are predominantly social spaces / third places with the social uses of these spaces addressing more than just book search or book purchasing needs [13]. Our suggestions address how to incorporate this aspect of libraries and bookshops for families using digital libraries.

Acknowledgements. We would like to thank the Tauranga and Hamilton libraries and bookshops for their support for this study along with Mrs Phillips for her invaluable assistance recruiting participant families. We acknowledge the support of the University of Waikato and our summer student research scholar, Laura Phillips, who admirably and capably conducted all observations. 


\section{$7 \quad$ References}

1. Cunningham, S.J.: Children in the physical collection: Implications for the digital library. Proc. Am. Soc. Inf. Sci. Technol. 48, 1-10 (2011).

2. Large, A., Nesset, V., Beheshti, J.: Children as information seekers: what researchers tell us. New Rev. Child. Lit. Librariansh. 14, 121-140 (2008).

3. Nadelson, S.G., Nadelson, L.S.: In Search of the Right Book: Considerations in Common Read Book Selection. J. Coll. Read. Learn. 43, 60-66 (2012).

4. Gross, M.: Children's information seeking at school: Findings from a qualitative study. Youth Inf.-Seek. Behav. Theor. Models Issues. 211-240 (2004).

5. Environics Research Group: Young Canadians in a wired world: Phase I. Ott. Media Aware. Netw. MNet Retrieved Sept. 29, 2002 (2001).

6. Raqi, S.A., Zainab, A.N.: Observing Strategies Used by Children When Selecting Books to Browse, Read or Borrow. J. Educ. Media Libr. Sci. 45, (2008).

7. Shenton, A.K., Dixon, P.: Sequential or selective access? Young people's strategies for finding information in non-fiction books. New Rev. Child. Lit. Librariansh. 9, 57-69 (2003).

8. Foggett, T.: Information literacy at the primary school level? Aust. Libr. J. 52, 55-63 (2003).

9. Hinze, A., Alqurashi, H., Vanderschantz, N., Timpany, C., Alzahrani, S.: Social Information Behaviour in Physical Libraries: Implications for the design of digital libraries. 2014 IEEE/ACM Joint Conference on Digital Libraries (JCDL), London. p. To Appear. IEEE (2014).

10.Reuter, K., Druin, A.: Bringing together children and books: An initial descriptive study of children's book searching and selection behavior in a digital library. Proc. Am. Soc. Inf. Sci. Technol. 41, 339-348 (2004).

11.Jones, M., Harwood, W., Buchanan, G., Lalmas, M.: Storybank: an indian village community digital library. Proceedings of the 7th ACM/IEEE Joint Conference on Digital Libraries (JCLD). pp. 257-258. ACM (2007).

12.Guha, M.L., Druin, A., Fails, J.A.: Cooperative inquiry revisited: Reflections of the past and guidelines for the future of intergenerational co-design. Int. J. Child-Comput. Interact. 1, 14-23 (2013).

13.Cunningham, S.J., Vanderschantz, N., Timpany, C., Hinze, A., Buchanan, G.: Social Information Behaviour in Bookshops: Implications for Digital Libraries. In: Aalberg, T., Papatheodorou, C., Dobreva, M., Tsakonas, G., and Farrugia, C.J. (eds.) Research and Advanced Technology for Digital Libraries. pp. 84-95. Springer Berlin Heidelberg (2013).

14.Timpany, C., Vanderschantz, N., Hinze, A., Cunningham, S.J., Wright, K.: Shared Reading of Interactive Children's Books. 16th International Conference on Asia-Pacific Digital Libraries, ICADL 2014, Chiang Mai, Thailand. p. To Appear. Springer Verlag (2014). 